\title{
Database Sumberdaya Lahan Pertanian Pangan Berkelanjutan Berbasis Remote Sensing dan Sistem Informasi Geografis di Subak Temaga Kecamatan Denpasar Timur
}

\author{
ARDHIA AYU PRADITHA, INDAYATI LANYA*), DAN MADE SRI SUMARNIASIH \\ Program Studi Agroekoteknologi, Fakultas Pertanian, Universitas Udayana \\ Jalan PB. Sudirman, Denpasar, Bali 80234 \\ ${ }^{*}$ E-mail: indahnet@yahoo.co.id
}

\begin{abstract}
Database of Sustainable Food Agricultural Land Resources Based on Remote Sensing and Geographical Information System at Subak Temaga East Denpasar Subdistricts. Subak Temaga doesn't yet have a database according to Government Regulation No. 25 of 2012 concerning Information System for Sustainable Food Agriculture Land (SFAL). A geospatial-based database needs to be compiled to implement these regulation. The research aims: compile a database of artificial resources, agricultural resources, land resources and human resources to support SFAL in Subak Temaga, create land ownership maps in Subak Temaga, compile an information system of SFAL and land ownership based on remote sensing and Geographic Information System (GIS). This research uses a survey method to obtain primary data, then doing the mapping to compile the information system based on geospatial. The research results: artificial resources (irrigation, jogging track/farm road), land resources (soil family, landform, slope, rainfall, land suitability, soil fertility), agricultural resources (types of farm commodities, productivity, agriculture tools and machinery, cropping pattern, types and dosage of fertilizer), human resources (name, address, age, last education, farmer status, ownership status, ownership large and boundary, profit-sharing system). Farmer status consists of 56 owner farmers $(30,9 \%)$ and 125 sharecropers $(69,1 \%)$. Land ownership status consist of 432 freehold polygons $(92,7 \%)$ and 34 non freehold polygons (23.8\%). Remote sensing is used to determine the boundaries of land ownership, GIS is used to compile a geospatial-based information system for LP2B and land ownership.
\end{abstract}

Keywords: Database, Sustainable Food Agricultural, Land Resources, GIS

\section{PENDAHULUAN}

Database diperlukan untuk seluruh bidang pembangunan, terutama dalam sektor pertanian. Perencanaan pembangunan pertanian didasarkan pada potensi sumberdaya buatan (SDB), sumberdaya pertanian (SDP), sumber-daya lahan (SDL), sumberdaya manusia (SDM). Kementrian 


\section{ARDHIA AYU PRADITHA et al. Database Sumberdaya Lahan Pertanian Pangan...}

Pertanian dalam Rencana Strategis (Renstra) memiliki misi untuk meningkatan ketahanan dan kedaulatan pangan, sehingga lahan sawah sebagai sumberdaya utama dalam pembangunan sektor pertanian perlu dilindungi keberadaannnya.

Pemerintah Indonesia telah menetapkan Undang-Undang (UU) No. 41/2009 tentang Perlindungan Lahan Pertanian Pangan Berkelanjutan (LP2B), dilengkapi dengan Peraturan Pemerintah (PP) No. 1/2011 tentang Alih Fungsi LP2B, PP No. 12/2012 tentang Insentif Perlindungan LP2B, PP No. 30/2012 tentang Pembiayaan Perlindungan LP2B, PP No. 25/2012 tentang Sistem Informasi LP2B, Peraturan Presiden No. 59/2019 tentang Pengendalian Alih Fungsi Lahan Sawah, Peraturan Menteri Agraria Tata Ruang/Badan Pertahanan Nasional (ATR/BPN) No. 19/2016 tentang Penetapan LP2B pada Wilayah yang Belum Terbentuk Rencana Tata Ruang Wilayah (RTRW), Peraturan Menteri Pertanian (Permentan) No. 41/ Permentan/OT.140/9/2009 tentang Kriteria Teknis Kawasan Peruntukan Pertanian, Permentan No. 07/Permentan/ OT.140/2/2012 tentang Pedoman Teknis Kriteria dan Persyaratan Kawasan, Lahan dan Lahan Cadangan Pertanian Pangan Berkelanjutan. Seluruh peraturan tersebut ditujukan untuk mencapai misi dan melindungi kelestarian lahan pertanian.

Berdasarkan PP No. 25/2012, pasal 6 ayat (1), penyusunan peraturan daerah terkait LP2B harus dilengkapi dengan database yang paling sedikit memuat informasi fisik alamiah, fisik buatan, status kepemilikan, jenis komoditas, kondisi SDM, luas dan lokasi lahan. Penelitian pemetaan lahan sawah di Kota Denpasar telah dilakukan oleh Lanya et al. (2019) dan menghasilkan klasifikasi sangat direkomendasikan, direkomendasikan, rekomendasi ber-syarat dan tidak direkomendasikan untuk LP2B. Subak Temaga termasuk $92,5 \%$ sangat direkomendasikan dan 7,5\% rekomendasi bersyarat dari 143,97 ha. Subak Temaga juga ditetapkan sebagai Ruang Terbuka Hijau Kota dalam RTRW Kota Denpasar Tahun 2011-2031. Namun, saat ini Subak Temaga hanya memiliki peta lokasi subak dan belum memiliki database sesuai PP No. 25/2012. Oleh karena itu, database LP2B perlu disusun untuk mendukung pelaksanaan pembangunan pertanian berkelanjutan Subak Temaga.

Database sesuai syarat tersebut dapat disusun menggunakan remote sensing dan Sistem Informasi Geografis (SIG). Remote sensing dan SIG telah digunakan oleh Lanya 
et al. (2019) untuk membuat peta rekomendasi LP2B Kota Denpasar dan Manalu et al. (2020) untuk menyusun sistem informasi SDM di Subak Anggabaya, Umalayu, Umadesa.

Berdasarkan uraian diatas, maka penelitian "Database Sumberdaya LP2B Berbasis Remote Sensing dan SIG di Subak Temaga Kecamatan Denpasar Timur" bertujuan: menyusun database SDB, SDP, SDL dan SDM untuk menunjang LP2B di Subak Temaga, membuat peta kepemilikan lahan sawah Subak Temaga berbasis remote sensing dan SIG, menyusun informasi sumberdaya LP2B dan kepemilikan lahan Subak Temaga berbasis remote sensing dan SIG.

\section{BAHAN DAN METODE}

Penelitian dilaksanakan dari Agustus sampai dengan November 2020 di Subak Temaga, Desa Penatih Dangin Puri, Kecamatan Denpasar Timur. Alat yang digunakan dalam penelitian ini, yaitu: (a) seperangkat hardware laptop, (b) software Microsoft Word 2019, (c) software Microsoft Excel 2019, (d) software SAS Planet, (e) software Locus GIS, (f) software QGIS 3.10, (g) Global Positioning System, (h) smartphone. Bahan yang digunakan dalam penelitian ini, yaitu: (a) Citra Satelit
WorldView Kota Denpasar tahun 2020, (b) peta Rupa Bumi Indonesia lembar Denpasar skala 1:25.000, (c) peta administrasi Kota Denpasar skala 1:25.000, (d) peta bidang tanah ATR/BPN, (e) peta subak Kota Denpasar tahun 2019, (f) data famili tanah, kemiringan lereng dan landform dari Penelitian Tanah dan Agroklimat (Puslittanak) (1994), (g) data kesesuaian lahan dan data curah hujan dari Trigunasih et al. (2018), (h) data kesuburan tanah dari Lanya et al. (2012), (i) data petani Subak Temaga dari arsip Balai Penyuluhan Pertanian (BPP) Denpasar Timur, (j) peta tentatif kepemilikan lahan Subak Temaga dari hasil digitasi, (k) kuisioner wawancara.

Penelitian dilaksanakan dengan menggunakan metode survei untuk mendapatkan data primer (SDP, SDB dan SDM), selanjutnya dilakukan pemetaan untuk menyusun sistem informasi LP2B dan kepemilikan lahan berbasis geospasial. Sumber data utama diperoleh dari citra dan responden sebagai sampel penelitian. Jumlah responden ditentukan menggunakan rumus Slovin (Amirin, 2011).

$$
\begin{aligned}
& n=\frac{181}{1+\left(181 \times\left(0,025^{2}\right)\right.} \\
& n=\frac{181}{5,525} \\
& n=32,76 \text { (dibulatkan menjadi } 33 \text { orang } \\
& \text { responden) }
\end{aligned}
$$




\section{ARDHIA AYU PRADITHA et al. Database Sumberdaya Lahan Pertanian Pangan...}

Tahapan penelitian meliputi: (a) studi literatur, (b) interpretasi citra, (c) survei lapangan, (d) reinterpretasi citra, (e) penyusunan sistem informasi sumberdaya LP2B dan kepemilikan lahan berbasis geospasial.

Studi literatur dilakukan dengan menghimpun data berdasarkan sumbersumber tertulis, baik berupa data hasil penelitian terdahulu mapun peta tematik yang sudah ada. Jenis data yang diperoleh dari tahap studi pustaka merupakan data sekunder, terdiri dari: peta bidang tanah dari situs ATR/BPN, data petani Subak Temaga dari BPP Denpasar Timur, citra WorldView Kota Denpasar dari software SAS Planet, data curah hujan dan data kesesuaian lahan dari penelitian Trigunasih et al. (2018), data status kesuburan tanah dari penelitian Lanya et al. (2012), data landform, famili tanah dan kemiringan lereng dari Puslittanak (1994).

Interpretasi citra dilakukan dengan mendigitasi poligon subak untuk mengetahui batas subak dan sebagai data spasial untuk penyusunan sistem informasi sumberdaya LP2B. Poligon subak diperoleh dari penelitian Lanya et al. (2019). Tahap berikutnya yaitu melakukan deliniasi batas kepemilikan lahan mengacu pada peta bidang tanah ATR/BPN. Batas kepemilikan lahan pada citra dicirikan dengan adanya garis sejajar yang dipisahkan oleh galengan. Setiap poligon diberikan nomor sebagai tanda kepemilikan lahan. Hasil proses deliniasi adalah peta tentatif kepemilikan lahan Subak Temaga.

Survei merupakan pengumpulan data secara langsung ke lapangan untuk memperoleh data SDP, SDB, SDM, serta memverifikasi batas kepemilikan lahan dengan menunjukkan hardcopy peta tentatif kepemilikan lahan kepada pangliman/petani. Adapun jenis sumber perolehan data, terdiri dari: (a) data primer, yaitu data yang diperoleh dari observasi, meliputi lokasi dan luas subak, jenis komoditas, pola tanam, alat dan mesin pertanian (alsintan), sistem bagi hasil, kualitas irigasi dan jogging track, panjang irigasi dan jogging track, lebar irigasi dan jogging track, sistem irigasi, luas dan batas kepemilikan, status petani, status kepemilikan, (b) data sekunder, yaitu data yang diperoleh dari wawancara dengan Petugas Penyuluh Lapang, pekaseh, pangliman, arsip Balai Penyuluhan Pertanian (BPP) Denpasar Timur dan hasil penelitian terdahulu, meliputi famili tanah, curah hujan, landform, kemiringan lereng, kesesuaian lahan, kesuburan tanah, sumber irigasi, produktivitas, jenis dan dosis pupuk, nama, alamat, usia, pendidikan petani. Luas 
kepemilikan lahan dihitung dengan mengukur poligon kepemilikan lahan menggunakan fitur measure area dalam software QGIS.

Reinterpretasi citra merupakan langkah untuk memperbaiki batas kepemilikan lahan dalam peta tentatif kepemilikan lahan Subak Temaga. Jika batas kepemilikan lahan tidak sesuai dengan kondisi di lapangan, maka dilakukan perbaikan poligon kepemilikan lahan langsung di lapangan menggunakan software LocusGIS yang telah terunduh di smartphone.

Penyusunan sistem informasi sumberdaya LP2B dan kepemilikan lahan disusun dengan metode join atribut dalam software QGIS. Join atribut antara poligon subak (data spasial) dan data SDL, SDP dan SDB (data atribut) menghasilkan sistem informasi sumberdaya LP2B, sedangkan join atribut antara poligon kepemilikan lahan (data spasial) dan data SDM (data atribut) menghasilkan sistem informasi kepemilikan lahan berbasis geospasial.

\section{HASIL DAN PEMBAHASAN}

Data SDP Subak Temaga meliputi: alsintan sebanyak satu buah traktor, empat buah mesin perontok padi, empat buah mesin brush cutter, sebelas buah penyemprot hama. Alat yang umum dimiliki oleh seluruh petani adalah cangkul dan arit. Komoditas utama yang dibudidayakan adalah padi dengan produktivitas 7,5 - 8,5 ton/ha. Pupuk yang digunakan yakni Urea (200 kg/ha) dan Phonska (200 kg/ha).

Data SDL Subak Temaga meliputi: kesesuaian lahan potensial tanaman padi sangat sesuai (S1), sedangkan tanaman hortikultura cukup sesuai (S2tc1) dengan faktor pembatas suhu. Famili tanah Typic tropaquepts, berlempung halus, campuran, tidak masam, isohipertemik, landform dataran volkan, kemiringan lereng mikro 03\% (Puslittanak, 1994). Curah hujan 1.182$1.590 \mathrm{~mm} /$ tahun (Trigunasih et al., 2018). Status kesuburan tanah Subak Temaga tergolong sedang (Lanya et al., 2012). Parameter untuk menilai status kesuburan tanah, yaitu: KTK, KB, C-organik, kadar P dan $\mathrm{K}$ total tanah.

Data SDB Subak Temaga meliputi: saluran irigasi dengan kualitas baik, sumber air dari Tukad Ayung, panjang $8.572 \mathrm{~m}$ dan lebar $1 \mathrm{~m}$. Sistem irigasi Subak Temaga termasuk semi teknis, karena bangunan jaringan irigasi belum seluruhnya dibuat permanen. Jogging track Subak Temaga memiliki panjang $1.288 \mathrm{~m}$ dan lebar 1,5 m. Peta saluran irigasi dan jogging track Subak Temaga tersaji pada Gambar 1. 


\section{ARDHIA AYU PRADITHA et al. Database Sumberdaya Lahan Pertanian Pangan...}

Data SDM Subak Temaga meliputi: Menengah Pertama (SMP), Sekolah nama petani dan pemilik, alamat, Menengah Atas (SMA) dan pendidikan, usia, status petani, sistem bagi Diploma/Sarjana (D1/S1). Usia dan hasil, luas, batas dan status kepemilikan. pendidikan petani Subak Temaga Jenjang pendidikan petani terdiri dari: Tidak berdasarkan status petani disajikan pada Sekolah (TS), Sekolah Dasar (SD), Sekolah $\quad$ Tabel 1 dan 2.

Tabel 1. Usia Petani Subak Temaga

\begin{tabular}{|c|c|c|c|c|}
\hline \multirow[b]{2}{*}{$\begin{array}{l}\text { Usia } \\
\text { (thn) }\end{array}$} & \multicolumn{4}{|c|}{ Status Petani } \\
\hline & $\begin{array}{c}\text { Petani } \\
\text { Peng-garap } \\
\text { (org) }\end{array}$ & $\begin{array}{c}\text { Presen-tase } \\
(\%)\end{array}$ & $\begin{array}{l}\text { Petani Pemi-lik } \\
\text { (org) }\end{array}$ & $\begin{array}{c}\text { Presen-tase } \\
(\%)\end{array}$ \\
\hline 2 & 3 & 4 & 5 & 6 \\
\hline $35-44$ & 9 & 5 & 4 & 2,2 \\
\hline $45-54$ & 35 & 19,3 & 16 & 8,8 \\
\hline $55-64$ & 40 & 22,1 & 18 & 9,9 \\
\hline $65-74$ & 32 & 17,7 & 13 & 7,2 \\
\hline $75-80$ & 9 & 5 & 5 & 2,8 \\
\hline Total & 125 & 69,1 & 56 & 30,9 \\
\hline
\end{tabular}

Sumber: BPP Denpasar Timur (2019)

Tabel 2. Jenjang Pendidikan Petani Subak Temaga

\begin{tabular}{lcccc}
\hline \multirow{2}{*}{ Pendidikan } & \multicolumn{4}{c}{ Status Petani } \\
\cline { 2 - 5 } & $\begin{array}{c}\text { Petani } \\
\text { Peng-garap } \\
(\text { org })\end{array}$ & $\begin{array}{c}\text { Presen-tase } \\
(\%)\end{array}$ & $\begin{array}{c}\text { Petani Pemi-lik } \\
\text { (org) }\end{array}$ & $\begin{array}{c}\text { Presen-tase } \\
(\%)\end{array}$ \\
\hline TS & 3 & 4 & 5 & 6 \\
SD & 32 & 17,7 & 15 & 8,3 \\
SMP & 53 & 29,3 & 21 & 11,6 \\
SMA & 17 & 9,3 & 9 & 4,9 \\
D1/S1 & 21 & 11,6 & 9 & 4,9 \\
\hline Total & 2 & 1,2 & 2 & 1,2 \\
\hline Sumberyyyyy & 125 & 69,1 & 56 & 30,9 \\
\hline
\end{tabular}

Sumber: BPP Denpasar Timur (2019)

Berdasarkan hasil deliniasi, jumlah poligon kepemilikan pada peta bidang tanah
ATR/BPN sebanyak 432 poligon, sedangkan berdasarkan observasi didapati 
jumlah kepemilikan lahan sebanyak 466 poligon, terdiri dari 432 poligon lahan hak milik $(92,7 \%)$ dan 34 poligon lahan non hak milik (7,38\%). Lahan hak milik adalah bidang tanah yang sudah terdaftar dan memiliki nomor registrasi pada peta bidang tanah ATR/BPN, sedangkan lahan non hak milik belum terdaftar dan belum memiliki nomor registrasi pada peta bidang tanah ATR/BPN.

Pemilik lahan di Subak Temaga berjumlah 323 orang, luas kepemilikan lahan rata-rata per pemilik yaitu 0,4 ha. Peta status petani Subak Temaga disajikan pada Gambar 2, sedangkan peta kepemilikan lahan Subak Temaga disajikan pada Gambar 3.

Sistem informasi sumberdaya LP2B (Gambar 4) dan sistem informasi kepemilikan lahan (Gambar 5) disusun dengan memanfaatkan teknologi remote sensing untuk mengetahui batas kepemilikan lahan melalui citra, serta program SIG untuk menyusun sistem informasi sumberdaya LP2B dan kepemilikan lahan berbasis geospasial.

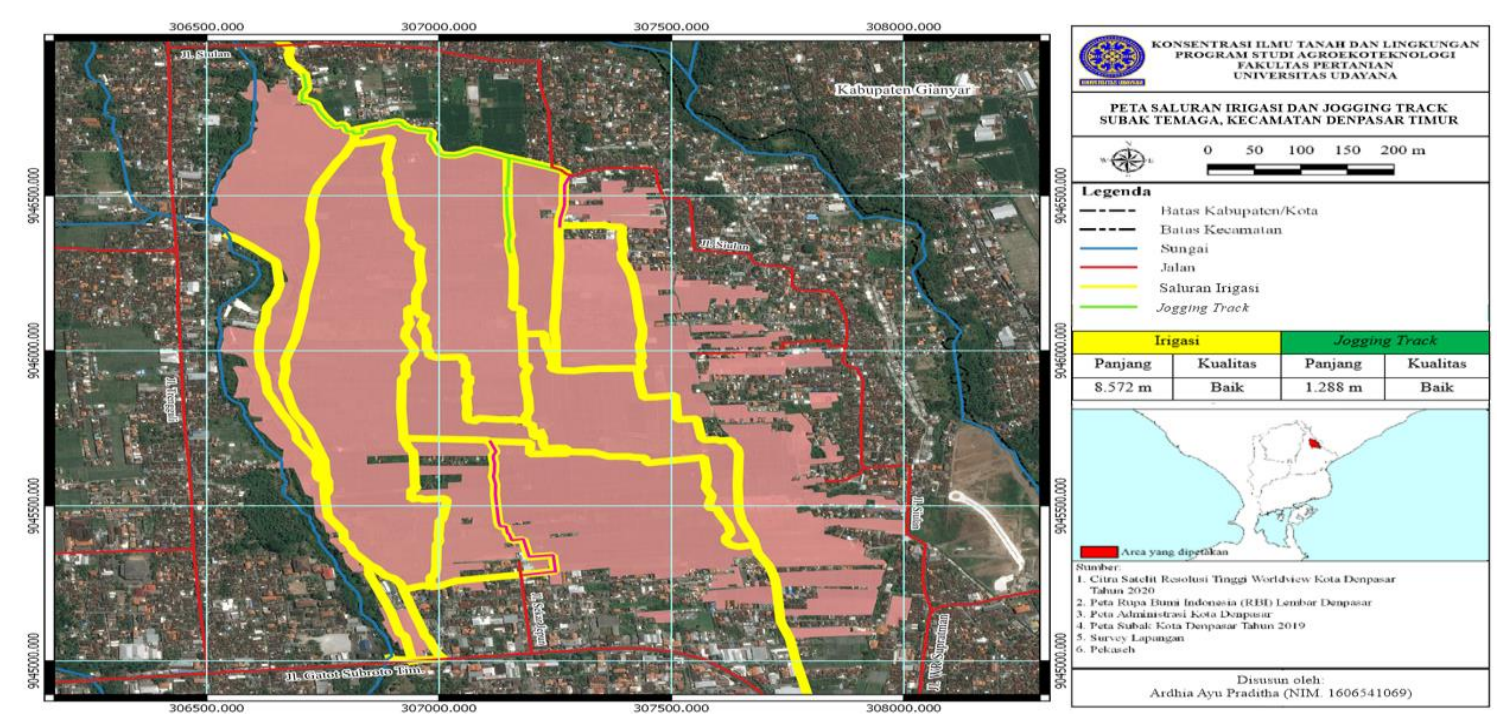

Gambar 1. Peta Saluran Irigasi dan Jogging Track Subak Temaga 
ARDHIA AYU PRADITHA et al. Database Sumberdaya Lahan Pertanian Pangan...
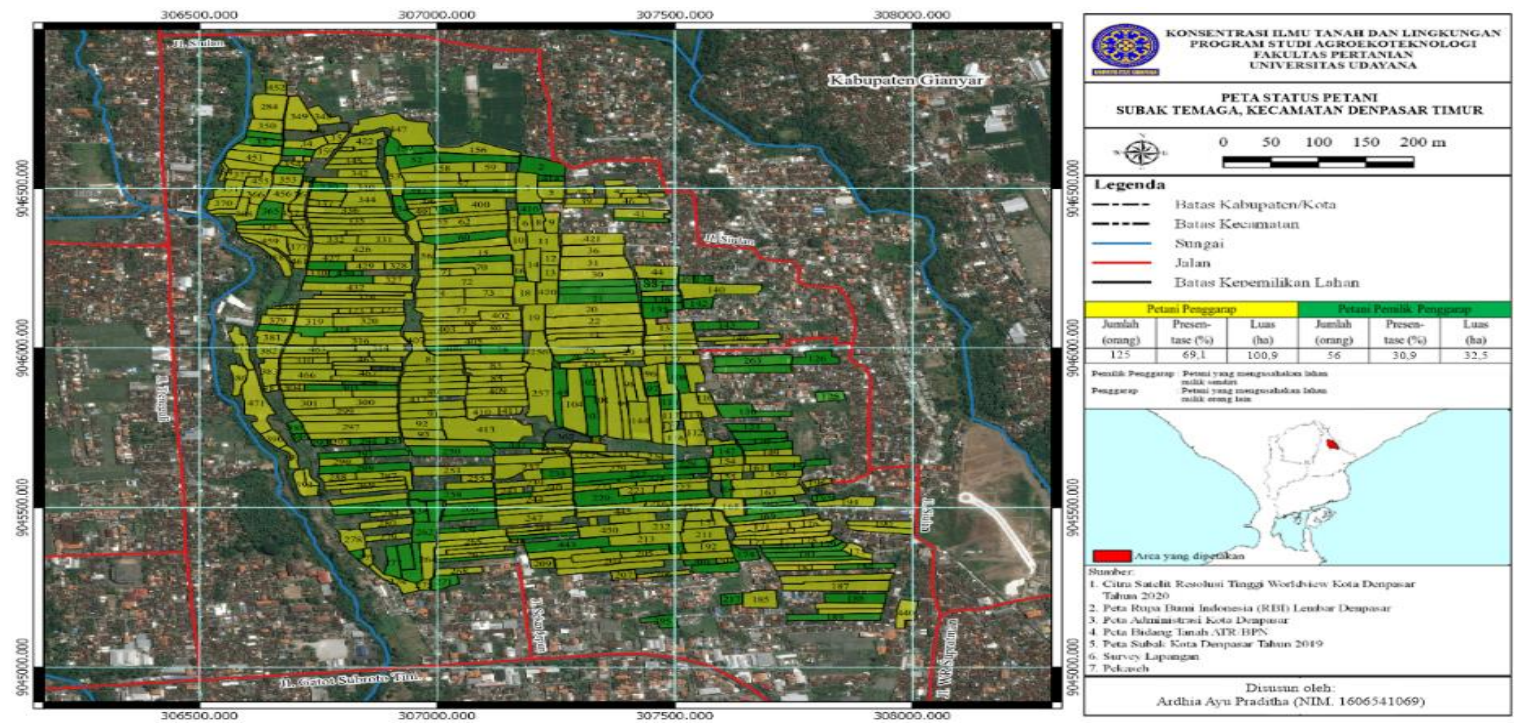

Gambar 2. Peta Status Petani Subak Temaga
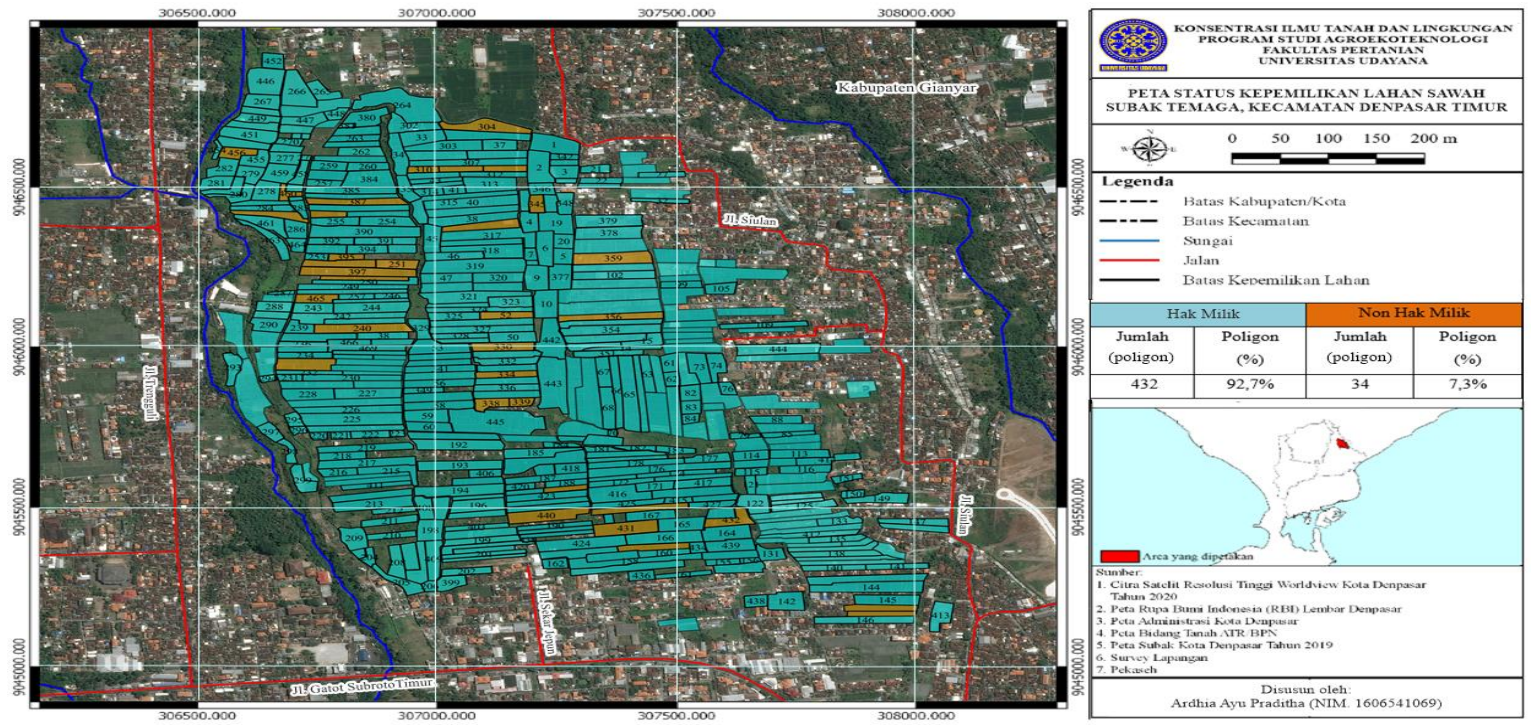

Gambar 3. Peta Status Kepemilikan Lahan Sawah Subak Temaga 


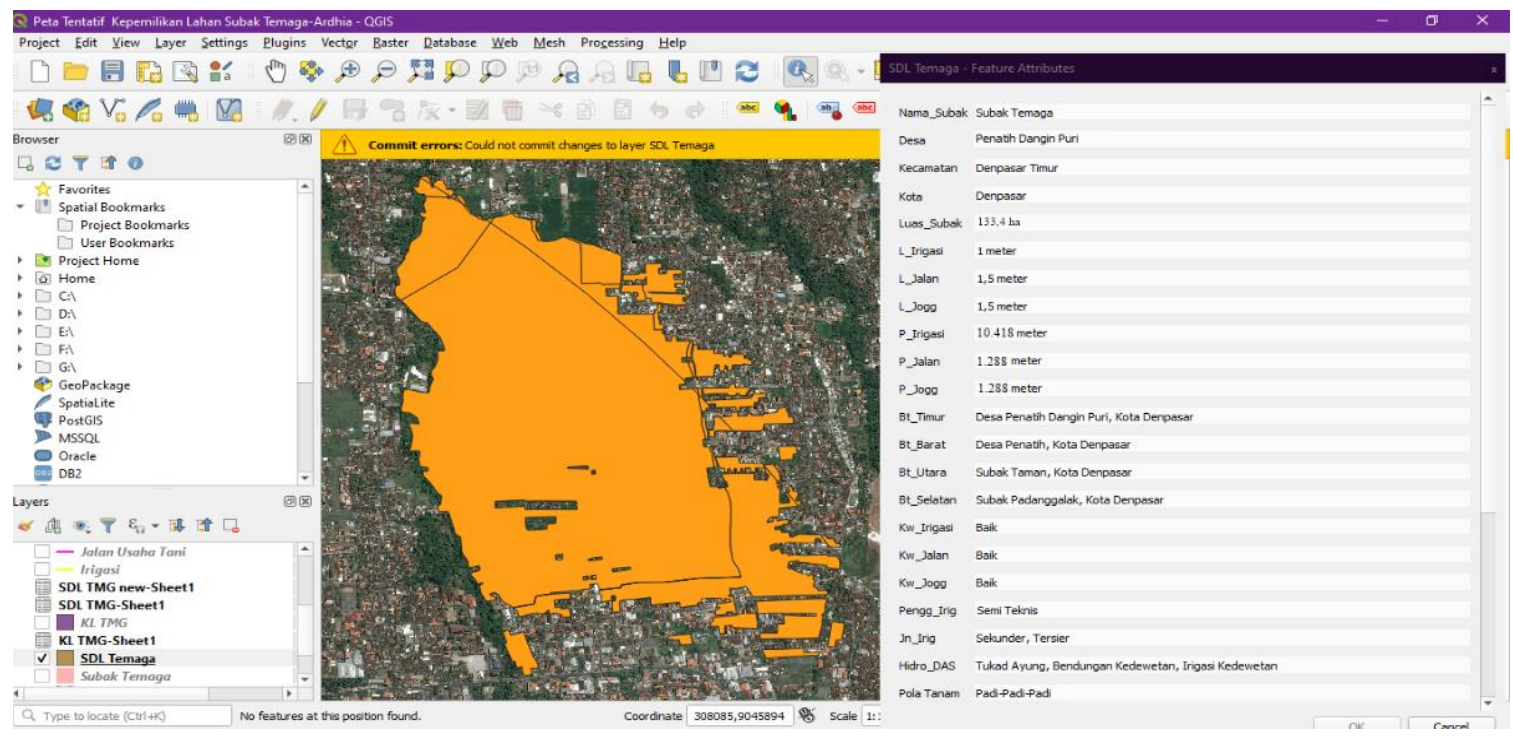

Gambar 4. Sistem Informasi Sumberdaya LP2B Subak Temaga

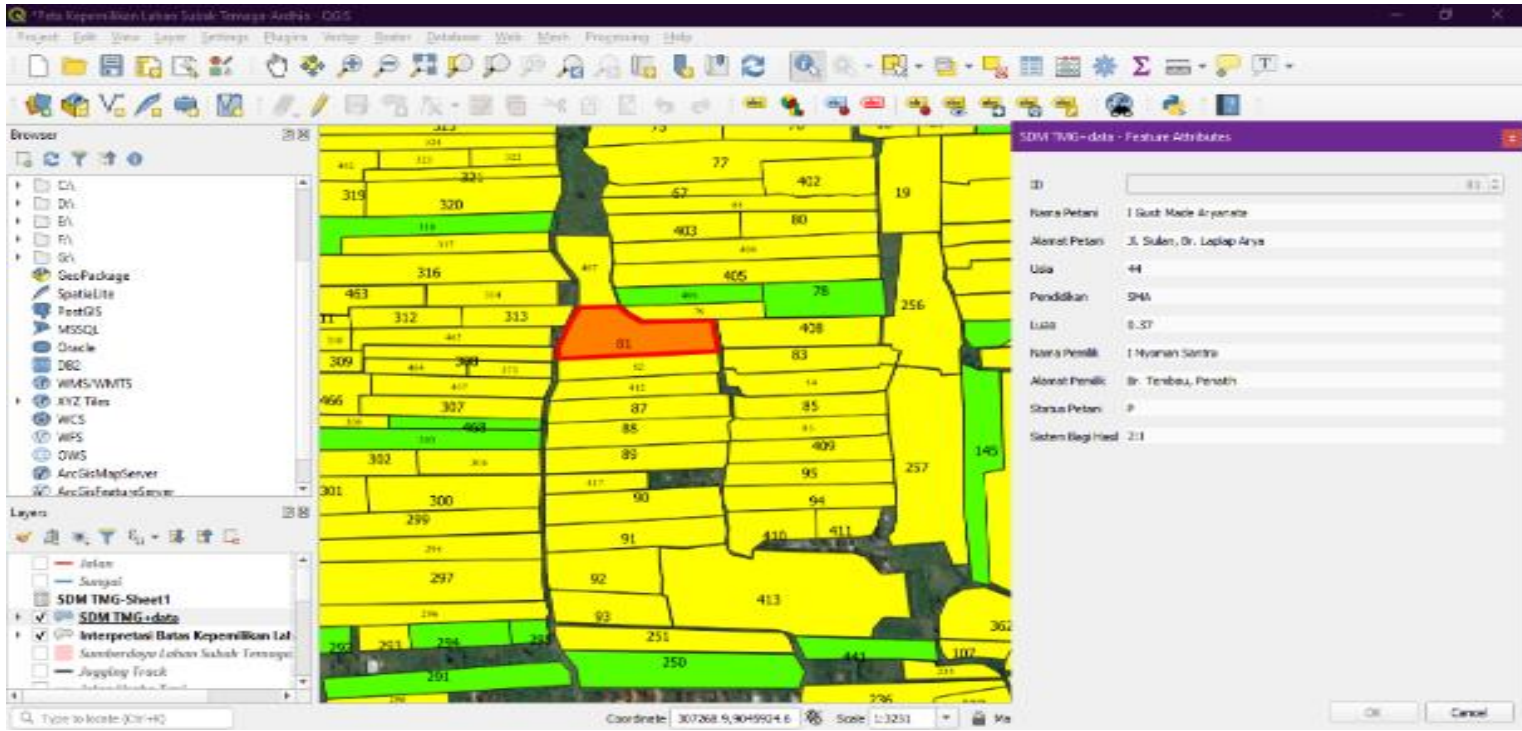

Gambar 5. Sistem Informasi Kepemilikan Lahan Subak Temaga

\section{Database Sumberdaya LP2B}

Jogging track Subak Temaga dapat diakses melalui Jalan Siulan (Gambar 1). Petani memanfaatkan jogging track sebagai jalan usahatani untuk mengangkut alsintan, pupuk dan hasil panen. Keberadaan jogging track di Subak Temaga secara langsung berpengaruh terhadap pendapatan petani. Jika petak sawah dapat diakses melalui jalan usahatani, maka harga jual gabah ke penebas Rp 320.000/are. Berbeda dengan petak sawah yang jauh dari jalan usahatani, maka 


\section{ARDHIA AYU PRADITHA et al. Database Sumberdaya Lahan Pertanian Pangan...}

harga jual menjadi Rp 300.000/are. Kualitas jogging track tergolong baik, namun memerlukan perbaikan di beberapa lokasi karena rusak, akibat lepasnya paving block.

Subak Temaga termasuk subak natak tiyis, yaitu subak yang memperoleh air irigasi dari tirisan subak lain (Subak Umalayu, Umadesa, Taman Poh Manis dan Anggabaya). Kualitas irigasi tergolong baik, dibuktikan dengan pola tanam padi-padipadi yang diterapkan petani Subak Temaga, dimana pola tanam ini membutuhkan air irigasi yang selalu tercukupi.

Pemilihan pola tanam padi-padi-padi dapat menjadi salah satu upaya intensifikasi produksi tanaman pangan dalam rangka memenuhi meningkatnya permintaan pasar akan pangan. Namun, penerapan pola tanam monokultur membuat lahan tergenang terus menerus, sehingga dapat menurunkan kadar bahan organik pada tanah dan menghancukan agregasi tanah yang dapat berdampak buruk pada pertanian berkelanjutan (Mohanti dan Painuli, 2004).

Kesesuaian lahan potensial untuk tanaman hortikultura umumnya cukup sesuai (S2tc1), sehingga sangat berpotensi untuk dikembangkan di Subak Temaga, dengan syarat dilakukan upaya perbaikan. Faktor pembatas drainase dapat diatasi dengan perbaikan saluran drainase untuk mempercepat pembuangan air. Upaya mengatasi faktor pembatas suhu dan curah hujan dapat dilakukan dengan pemilihan musim tanam sesuai syarat tumbuh tanaman (musim hujan atau kemarau), sehingga tanaman dapat tumbuh optimal. Namun demikian, tanaman hortikultura yang dibudidayakan petani Subak Temaga hanya berupa bunga-bungaan (pacar, ratna dan gumitir). Berdasarkan hasil wawancara dengan pangliman di setiap munduk, petani Subak Temaga tidak menanam komoditas hortikultura karena alasan berikut: (1) air irigasi selalu tercukupi, sehingga petani terdorong untuk menanam padi sepanjang tahun, (2) siklus hidup tanaman palawija relatif pendek, namun membutuhkan waktu, tenaga dan biaya operasional yang tinggi, sedangkan harga jual tidak stabil, terutama saat panen raya, (3) bantuan benih dari Pemda Kota Denpasar hanya untuk tanaman padi, (4) komoditas hortikultura belum memiliki jaminan pasar, karena selama ini penebas hanya mau membeli hasil panen padi.

Lanform Subak Temaga adalah dataran volkan. Tanah yang tersusun dari bahan induk batuan volkan mempunyai cadangan mineral lebih banyak dibandingkan tanah yang tersusun dari batuan sedimen atau tufa masam, sehingga 
kesuburan tanahnya lebih baik (Soekardi et al., 1994).

Tingkat kesuburan tanah Subak Temaga tergolong sedang (Lanya et al.,2012). Ini diakibatkan oleh kadar Corganik yang rendah $(1,69 \%)$ dan P-tersedia yang sangat rendah (2,58 ppm). Penurunan kualitas lahan menuntut petani untuk semakin bijak mengatur pola budidayanya agar kemampuan tanah dapat dipertahankan atau ditingkatkan untuk mendukung upaya peningkatan produktivitas tanaman. Selain itu, penggunaan pupuk organik yang dikombinasikan dengan pupuk anorganik juga dapat berpengaruh untuk meningkatkan kadar C-organik, N-total, P-total dan Ptersedia (Suwartil dan Sukritiyunobowo, 2009).

Komoditas utama petani Subak Temaga adalah padi sawah varietas Ciherang dan Cigeulis. Produtivitas padi sawah lebih rendah pada musim hujan (7,5 ton/ha), dibandingkan pada musim kering (8,5 ton/ha). Hal ini disebabkan karena curah hujan yang tinggi umumnya dapat membuat tanaman padi rebah (Suarjaya et al., 2017).

Jenis pupuk yang digunakan petani Subak Temaga (Urea dan Phonska) di subsidi oleh Pemda Kota Denpasar, sehingga setiap petani hanya diperbolehkan membeli pupuk sesuai kebutuhan yang telah diatur dalam Rencana Definitif Kebutuhan Kelompok (RDKK) Subak Temaga. Harga yang dibebankan kepada petani untuk pupuk Urea yakni Rp 90.000/50kg, sedangkan Phonska sebesar Rp115.000/50kg.

Mayoritas petani Subak Temaga merupakan penduduk asli Banjar Laplap, Desa Penatih Dangin Puri, sedangkan usia petani Subak Temaga berkisar antara 38-80 tahun. Berdasarkan Tabel 1 dapat diketahui bahwa total petani yang berada pada kategori usia produktif atau dibawah 64 tahun $(67,4 \%)$ lebih mendominasi dibandingkan dengan petani pada kategori lanjut usia (32,6\%). Meskipun usia produktif memiliki presentase lebih tinggi, namun hal ini akan menjadi permasalahan serius ketika petani yang sekarang berusia produktif berubah menjadi nonproduktif tanpa adanya regenerasi usia produktif yang baru (Cahyaningtiyas, 2021).

Usia merupakan salah satu faktor yang berhubungan dengan kemampuan kerja petani dalam melaksanakan kegiatan usahatani. Meskipun demikian, terdapat petani penggarap $(32,5 \%)$ dan petani pemilik $(13,8 \%)$ di Subak Temaga telah berusia lanjut. Keberadaan petani berusia lanjut disebabkan karena sudah bekerja sebagai petani sejak usia muda, sehingga 


\section{ARDHIA AYU PRADITHA et al. Database Sumberdaya Lahan Pertanian Pangan...}

tetap memilih kegiatan usahatani sebagai sumber pendapatan.

Tabel 2 menunjukkan bahwa baik petani penggarap maupun petani pemilik umumnya memiliki pendidikan formal rendah (tamat SD). Petani dengan pendidikan formal tinggi (D1/S1) melakukan usahatani karena telah pensiun dari pekerjaan utama sebagai pegawai negeri sipil. Hasil penelitian di Subak Angabaya, Umalayu dan Umadesa oleh Manalu (2020) dan di Subak Sembung oleh Cahyaningtiyas (2021) menunjukkan hasil yang serupa, yakni pendidikan formal petani umumnya tamat SD dan tidak sekolah. Keterbatasan pendidikan menyebabkan petani cenderung sulit mengadopsi teknologi dan inovasi baru dalam mengembangkan kegiatan usahatani, sementara teknologi dan inovasi sangat diperlukan dalam meningkatkan kualitas dan kuantitias produk bertanian.

Upaya yang dapat dilakukan untuk mengatasi hal tersebut yakni dengan mengembangkan SDM melalui penyuluhan pertanian yang dilaksanakan secara berkelanjutan guna meningkatkan keterampilan, kemauan, pengetahuan dan pendapatan petani dalam meningkatkan produktivitas kegiatan usahatani. Hal ini sesuai dengan pernyataan Prayitno et al. (2014) bahwa pengetahuan tidak hanya didapat melalui pendidikan formal, khusus untuk pengetahuan tentang pertanian dapat diperoleh juga dari pendidikan informal berupa penyuluhan dan kursus.

Berdasarkan hasil penelitian dapat diketahui bahwa SDL, SDP dan SDB Subak Temaga telah memenuhi kriteria sebagai LP2B, sesuai yang tercantum dalam Peraturan Menteri Pertanian No. 07/Permentan/OT.140/2/ 2012 tentang Pedoman Teknis Kriteria dan Persyaratan Kawasan, Lahan dan Lahan Cadangan Pertanian Pangan Berkelanjutan. Hal ini didasari oleh fakta bahwa: (a) Subak Temaga memiliki hamparan lahan lebih dari 5 ha, (b) kesesuaian lahan potensial untuk tanaman pangan pokok (padi sawah) sangat sesuai, (c) memiliki infrastruktur dasar seperti saluran irigasi dan jalan usahatani yang digunakan sebagai sarana dan sarana prasarana hasil pertanian, (d) produktivitas tanaman pangan pokok di Subak Temaga sudah diatas 3 ton/ha, (e) menerapkan intensitas pertanaman untuk tanaman pangan diatas satu kali setahun, (f) memiliki air irigasi yang selalu tersedia sepanjang tahun.

Potensi SDM Subak Temaga tergolong cukup baik, namun diperlukan pembinaan SDM agar petani dapat mendukung pelaksanaan pertanian 
berkelanjutan. Dengan dilengkapi oleh database LP2B dan kepemilikan lahan berbasis geospasial, maka Subak Temaga layak ditetapkan sebagai LP2B.

\section{Kepemilikan Lahan di Subak Temaga}

Berdasarkan Gambar 2 dapat diketahui bahwa jumlah petani penggarap lebih banyak dibandingkan petani pemilik. Hal ini disebabkan karena hanya sebanyak 56 orang $(17,3 \%)$ pemilik lahan yang mau mengelola lahan miliknya sendiri, sedangkan 267 orang pemilik lahan lainnya $(82,7 \%)$, lebih memilih bekerja di sektor nonpertanian dan menyerahkan lahan miliknya untuk dikelola orang lain/penggarap. Ini terkait dengan letak Subak Temaga yang berada di perkotaan, sehingga terdapat banyak alternatif pekerjaan yang dianggap lebih menjanjikan dari bertani.

Petani penggarap mendapat keuntungan melalui sistem bagi hasil 2:1. Aturan dalam sistem ini mewajibkan petani penggarap untuk menanggung seluruh biaya operasional, sedangkan pemilik hanya menyediakan lahan. Berdasarkan sistem bagi hasil tersebut, semakin luas lahan yang mampu digarap oleh petani penggarap, maka semakin tinggi pendapatan yang dapat diperoleh petani penggarap.
Gambar 3 menunjukkan bahwa jumlah poligon kepemilikan lahan Subak Temaga yang telah di verifikasi ke lapangan berbeda dengan jumlah poligon kepemilikan lahan yang tercantum dalam peta tanah ATR/BPN. Perbedaan tersebut disebabkan oleh adanya bidang tanah yang belum terdaftar di Kementrian ATR/BPN (7,3\%). Hal ini menunjukkan bahwa masih terdapat pemilik lahan yang minim pengetahuan dan kesadaran hukum terkait peraturan pendaftaran tanah. Salah satu faktor yang mendorong hal tersebut yakni adanya presepsi bahwa menyelesaikan administrasi pertanahan membutuhkan waktu dan biaya yang besar, prosedur dan persyaratan pembuatan sertifikat tanah yang rumit, serta membuat Pajak Bumi dan Bangunan (PBB) atau pajak-pajak lainnya akan semakin mahal.

Berdasarkan hasil penelitian dapat diketahui bahwa tingkat ketelitian interpretasi citra mencapai $93 \%$ pada penelitian kepemilikan lahan di Subak Temaga. Penelitian lainnya dilakukan di Subak Sembung oleh Cahyaningtiyas (2021) dan menghasilkan tingkat ketelitian interpretasi citra sebesar 95\%, serta di Kabupaten Gianyar oleh Lanya et al. (2016) menghasilkan tingkat ketelitian interpretasi citra sebesar $98 \%$. 
ARDHIA AYU PRADITHA et al. Database Sumberdaya Lahan Pertanian Pangan...

\section{Sistem Informasi Sumberdaya LP2B dan}

Kepemilikan Lahan Sawah Berbasis

Geospasial

Sistem informasi sumberdaya LP2B dan kepemilikan lahan lebih cepat dan mudah jika disusun menggunakan teknologi remote sensing dan SIG. Hal ini sesuai dengan pernyataan Suarjaya et al. (2017) bahwa program QGIS dapat digunakan untuk menganalisis, mengolah dan menyajikan database sumberdaya subak secara cepat dan mudah dibandingkan dengan cara manual. Penggunaan cara manual memerlukan poses analisis yang lebih lama dan lebih rumit hal ini dikarenakan penyajian data dalam bentuk peta dan tabel dibuat terpisah. Adanya peta bidang tanah ATR/BPN dan kemudahan dalam mengunduh citra satelit resolusi tinggi sangat memudahkan dalam proses deliniasi poligon kepemilikan lahan. Informasi sumberdaya LP2B dapat ditampilkan dengan meng-klik poligon subak, kemudian akan muncul jendela data atribut seperti yang disajikan pada Gambar 4, sedangkan informasi kepemilikan lahan dapat ditampilkan dengan meng-klik salah satu poligon kepemilikan lahan, kemudian akan muncul jendela data atribut poligon yang dipilih seperti disajikan pada Gambar 5.

\section{SIMPULAN}

Berdasarkan hasil penelitian, diperoleh kesimpulan sebagai berikut: (a) database SDL, SDP dan SDB tergolong baik, sedangkan database SDM tegolong cukup baik, sehingga Subak Temaga layak ditetapkan sebagai LP2B dan dapat mendukung pembangunan pertanian berkelanjutan, (b) hasil digitasi kepemilikan lahan di Subak Temaga berjumlah 466 poligon, terdiri dari: 432 poligon lahan hak milik $(92,7 \%)$ dan 34 poligon lahan non hak milik $(7,38 \%)$. Status petani di Subak Temaga terdiri dari: 125 orang petani penggarap $(69,1 \%)$ dan 56 orang petani pemilik $(30,9 \%)$, (c) Teknologi remote sensing digunakan untuk mengetahui batas kepemilikan lahan, serta program SIG digunakan untuk menyusun sistem informasi sumberdaya LP2B dan kepemilikan lahan berbasis geospasial.

\section{DAFTAR PUSTAKA}

Amirin, T. (2011). Populasi dan Sampel Penelitian. Jakarta: Erlangga.

Badan Penelitian dan Pengembangan Pertanian. (1994). Peta Tanah Semi Detail Lembar Nusa Dua-Padang Bai. Puslittanak: Bogor.

Cahyaningtiyas, I. (2021). Aplikasi Remote Sensing dan GIS untuk Menunjang Database LP2B dan Agrowisata di Subak Sembung. Skripsi. Program Studi Agroekoteknologi. Universitas Udayana. Denpasar, 113 hal. 
Lanya, I., Subadiyasa, N. N., Ratna Adi, I. G. P., \& Sardiana, I. K. (2012). Inventarisasi dan Deskripsi Potensi Sumberdaya Lahan Berbasis Remote Sensing dan GIS di Kota Denpasar. Laporan Akhir. Universitas Udayana. Denpasar.

Lanya, I., Trigunasih, N. M., Dibia, I N., Sardiana, I. K., \& Arthagama, I. D. M. (2019). Digitasi Peta pada Pemetaan Lahan Subak Kota Denpasar. Laporan Akhir. Universitas Udayana. Denpasar.

Manalu, T. J., Lanya, I., \& Ratna Adi, I. G. P. (2020). Pemetaan Kepemilik an Lahan Sawah dan Sumberdaya Manusia Berbasis Geospasial di Subak Anggabaya, Umalayu dan Umadesa. Jurnal Agroekoteknologi Tropika. 9(3): $166-179$.

Mohanty, M., \& Painuli D. K. (2004). Land preparatory tillage effect on soil physical environment and growth and yield of rice in a Vertisol. Journal of the Indian Society of Soil Science 51(3): $223-228$

Peraturan Pemerintah No. 25 Tahun 2012 tentang Sistem Informasi Lahan Pertanian Pangan Berkelanjutan. Lembaran Negara No. 5283. Jakarta: Sekretariat Negara. http://jdihn.go.id (diakses 25 Desember 2019)

Peraturan Menteri Pertanian No. 07/Permentan/OT.140/2/2012 tentang Pedoman Teknis Kriteria dan Pesyaratan Kawasan, Lahan dan Lahan Cadangan Pertanian Pangan Berkelanjutan. Lembaran Negara No. 205. Jakarta: Sekretariat Negara. http://psp.pertanian.go.id (diakses 31 Maret 2021)

Prayitno, W., Saam, Z., \& Nurhidayah, T. (2014). Hubungan Pengetahuan, Persepsi dan Perilaku Petani dalam Penggunaan Pestisida pada
Lingkungan. Jurnal Kajian Lingkungan. 2(2): $220-237$.

Soekardi, M., \& Adiningsih, J. S., \& Prawirasumantri, J. (1994). The Characteristics of Rice Soils of Indonesia. Bogor: Puslittanak.

Suarjaya, D. G., Lanya, I., \& Ratna Adi, I G. P. (2017). Aplikasi Remote Sensing dan SIG untuk Pemetaan Informasi Sumberdaya Lahan Sawah di Kecamatan Kuta dan Kuta Utara. Jurnal Agroekoteknologi Tropika. 6(3): $239-248$.

Suwatril, H. M., \& Sukristiyonubowo). (2009. Pengaruh Pemberian Pupuk Organik Cair terhadap Pertumbuhan dan Hasil Padi varietas Ciherang. Prosiding Seminar Nasional dan Dialog Sumberdaya Lahan Pertanian. Bogor: Balittanah.

Trigunasih, N. M., Lanya, I., Subadiyasa, N. N., \& Hutauruk, J. K. (2018). Model of Numerical Classification for Sustainable Agriculture in Badung Regency and Denpasar City. IOP Conf. Ser.: Earth and Environ. Sci. 123 012030 . 